San Jose State University

SJSU ScholarWorks

Master's Theses

Master's Theses and Graduate Research

1994

\title{
Evaluating coaching skills training through subordinate's view of organizational climate and managerial skills
}

Laura Whitney McGibben

San Jose State University

Follow this and additional works at: https://scholarworks.sjsu.edu/etd_theses

\section{Recommended Citation}

McGibben, Laura Whitney, "Evaluating coaching skills training through subordinate's view of organizational climate and managerial skills" (1994). Master's Theses. 780.

DOI: https://doi.org/10.31979/etd.mkv9-2cvn

https://scholarworks.sjsu.edu/etd_theses/780

This Thesis is brought to you for free and open access by the Master's Theses and Graduate Research at SJSU ScholarWorks. It has been accepted for inclusion in Master's Theses by an authorized administrator of SJSU ScholarWorks. For more information, please contact scholarworks@sjsu.edu. 


\section{INFORMATION TO USERS}

This manuscript has been reproduced from the microfilm masúer. UMI films the text directly from the original or copy submitted. Thus, some thesis and dissertation copies are in typewriter face, while others may be from any type of computer printer.

The quality of this reproduction is dependent upon the quality of the copy submitted. Broken or indistinct print, colored or poor quality illustrations and photographs, print bleedthrough, substandard margins, and improper alignment can adversely affect reproduction.

In the unlikely event that the author did not send UMI a complete manuscript and there are missing pages, these will be noted. Also, if unauthorized copyright material had to be removed, a note will indicate the deletion.

Oversize materials (e.g., maps, drawings, charts) are reproduced by sectioning the original, beginning at the upper left-hand corner and continuing from left to right in equal sections with small overlaps. Each original is also photographed in one exposure and is included in reduced form at the back of the book.

Photographs included in the original manuscript have been reproduced xerographically in this copy. Higher quality $6^{\prime \prime} \times 9^{\prime \prime}$ black and white photographic prints are available for any photographs or illustrations appearing in this copy for an additional charge. Contact UMI directly to order.

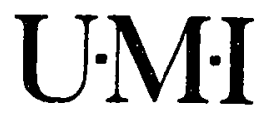

University Microfilms International

A Bell \& Howell Information Company

300 North Zeeb Road. Ann Arbor. MI 48106-1346 USA

$313 / 761-4700 \quad 800 / 521-0600$ 

Order Number 1358204

Evaluating coaching skills training through subordinate's view of organizational climate and managerial skills

McGibben, Laura Whitney, M.S.

San Jose State University, 1994 



\title{
EVALUATING COACHING SKILLS TRAINING THROUGH SUBORDINATE'S VIEW OF ORGANIZATIONAL CLIMATE AND MANAGERIAL SKILLS
}

\author{
A Thesis \\ Presented to \\ the Faculty of the Department of Psychology \\ San Jose State University \\ In Partial Fulfillment \\ of the Requirements for the Degree \\ Master of Science
}

by

Laura Whitney McGibben

May, 1994 
Copyright @ 1994 All rights reserved Laura Whitney McGibben 
APPROVED FOR THE DEPARTMENT OF PSYCHOLOGY

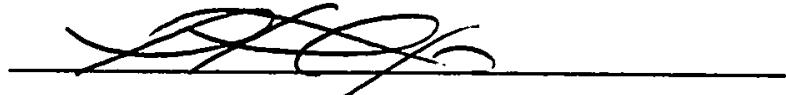

Howard Tokunaga, Ph. D. Associate Professor \& Director IndustrialVOrganizational Psychology Program

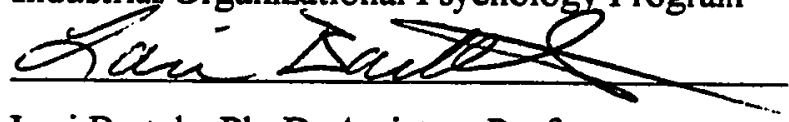

Lori Bartels, Ph. D. Assistant Professor Industria/Organizational Psychology Program

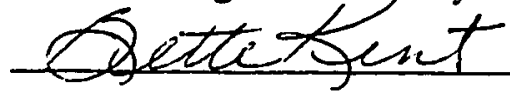

Bette Kent, Human Resources Specialist

Human Resources Development, Lockheed Missiles and Space Company, Inc.

APPROVED FOR THE UNIVERSITY

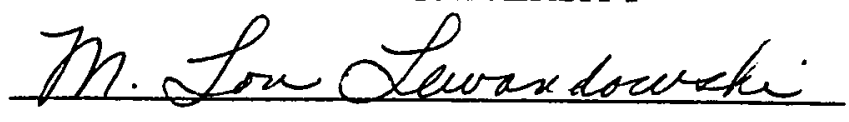




\section{ABSTRACT \\ EVALUATING COACHING SKILLS TRAINING THROUGH SUBORDINATE'S \\ VIEW OF THE ORGANIZATIONAL CLIMATE AND MANAGERIAL SKILLS \\ by Laura W. McGibben}

This study evaluated the effectiveness of a management training program on coaching skills. Forty-eight subordinates whose managers attended the training were surveyed one week prior, one week after and ten weeks after the training. These surveys determined if the subordinates' ratings of the organizational climate's openness toward coaching and their managers' coaching skills changed over time. Whether the training participants continued using their coaching skills was also explored.

Significant results revealed that the coaching skills improved one: week after the training. Also, managers who continued using coaching skills were rated as more effective managers. Conversely, the managers did not significantly improve their coaching skills ten weeks after the training. Finally, the organizational climate's openness toward coaching did not significantly change over time. This study has important implications for further coaching training and provides recommendations for introducing continuous reinforcement into the coaching process. 


\section{ACKNOWLEDGMENTS}

I would like to express my sincere appreciation for Howard Tokunaga and Lori Bartels who have patiently made suggestions which have improved the quality of this study!

Bruce Goeas has been a wonderfully inspiring mentor who gave me the opportunity to gain "real-world" experience with coaching. I am deeply grateful for his advice and support which made this thesis possible.

A special thanks also goes to Bette Kent and Alice Musbach who have inspired and encouraged me throughout my endeavors. 
TABLE OF CONTENTS

SECTION

INTRODUCTION

METHGD

Subjects.

Materials.

Procedure

RESULTS

DISCUSSION.

REFERENCES.

APPENDICES.

Appendix A. Survey - first section................................ 48

Appendix B. Survey - second section, pre-test............... 49

Appendix C. Survey - second section, first post-test ..... 50

Appendix D. Survey - second section, second post-test.. 51

Appendix E. Survey - third section................................. 52 


\section{LIST OF TABLES}

TABLE

PAGE

1. Means and Standard Deviations of Climate and Skills Variables at Three Time Periods

2. Means and Standard Deviations for Climate and Skills Variable MANOVA.................................... 28

3. Means and Standard Deviations for Skills and Used/Not Used MANOVA.

4. Means and Standard Deviations of Climate and Skills Variables at Three Time Periods

- For Entire Sample.

5. Means and Standard Deviations of Climate and Skills Variables at Three Time Periods -Excluding Seventeen Subjects. 
Evaluating Coaching

Evaluating Coaching Skills Training Through Subordinate's View of

Organizational Climate and Managerial Skills

Laura Whitney McGibben

San Jose State University

Running head: EVALUATING COACHING 


\begin{abstract}
This study evaluated the effectiveness of a management training program on coaching skills. Forty-eight subordinates whose managers attended the training were surveyed one week prior, one week after and ten weeks after the training. These surveys determined if the subordinates' ratings of the organizational climate's openness toward coaching and their managers' coaching skills changed over time. Whether the training participants continued using their coaching skills was also explored. Significant results revealed that the coaching skills improved one week after the training. Also, managers who continued using coaciing skills were rated as more effective managers. Conversely, the managers did not significantly improve their coaching skills ten weeks after the training. Finally, the organizational climate's openness toward coaching did not significantly change over time. This study has important implications for further coaching training and provides recommendations for introducing continuous reinforcement into the coaching process.
\end{abstract}


Evaluating Coaching Skills Training Through Subordinate's View of Organizational Climate and Managerial Skills

Organizational changes in the nineties are requiring managers to effectively balance their interpersonal and technical skills. Managers are being forced to develop new flexible strategies to manage competitive pressures from a changing global economy. According to Kanter (1989), strategy and structure changes are evident as corporations reduce their management staff and hierarchy levels; many organizations are replacing vertical means of communication with horizontal ties between co-workers. Organizations are searching for alternative forms of management that will increase the commitment, initiative and innovation of their workforce without sacrificing coordination (Harrison, 1983; Kanter, 1983; Walton, 1985).

The management style of coaching is an important empowerment tool that enables managers to increase the productivity of their employees. This technique is currently considered an effective way for managers to develop trusting and supportive relationships with their subordinates while improving their own skills and capabilities. This study evaluated the effectiveness of a coaching skills training program which was conducted for upper management within a medium-sized organization.

\section{Definitions of Coaching}

The concept of coaching was first seen in literature during the 1950's as a way of discussing an employee's progress and problems during the annual job review. Twenty 
years later coaching emerged as a management technique which was compared with sports coaching. In the eighties coaching was adopted as a training technique which became associated with career counseling, mentoring and management development (Evered \& Selman, 1989).

Coaching as a management style has been defined and described in various ways. According to Evered and Selman (1989), coaching is the art of communicating support and expected results. The term "coach" is significant since it implies mutual support, enthusiasm and a demand for improvement. The coach's job is neither to give information as the "expert," nor to be a mentor in teaching the organizational ropes. Rather, the manager-coach is concerned with how each employee views and interprets the organization.

Aurelio and Kennedy (1991) describe the manager-coach as a motivator for his or her "team." For example, the coach should be aware of which employees do specific tasks best or who needs scheduling advice. Coaching is a continuous process which provides constructive feedback and keeps employees focused on their goal.

More specifically, some consider coaching to be a form of on-the-job training in which the manager works directly with each employee to develop or improve job-related skills (Knippen \& Green, 1990). Kinlaw (1989) considers coaching as the daily conversation which is an opportunity to clarify goals, establish priorities and listen to concerns. Most importantly, the manager should use these coaching conversations to encourage subordinates by praising them for their problem solving and planning. 


\section{Benefits of Coaching}

Coaching became an important management concept when it was discovered that the employee's role was just as dynamic as the leader for whom he or she worked. Therefore, the emphasis shifted from studying the traits of the "ideal" leader to looking at follower's attributions of leaders that make the followers respond positively or negatively to the leader (Lord, DeVader, \& Alliger, 1986). Consequently, researchers focused their attention on the follower in the leadership process. This increased interest in the follower is compatible with the current changes in organizations since participative management with follower involvement appears to increase loyalty and profitability (Hollander \& Offerman, 1990). Therefore, in the last ten years, the management experts have provided a profusion of literature which focuses on the benefits of coaching, as well as its potential barriers.

Organizations are realizing the benefits of the coaching management style. Managers who adopt a coaching style encourage a supportive atmosphere that may result in stronger teams, increased productivity and a less stressful workplace (Orth, Wilkinson, \& Benfari, 1987). Aurelio and Kennedy (1991) mention three important benefits to coaching. First, employees will respond to the constant support and feedback by increasing their motivation. Second, the team spirit and ownership encouraged through coaching will augment the member's personal development. Third, the employees will convey improved group performance by focusing on cooperation and growth. 
Managers who use coaching as a form of on-the-job training emphasize that effective coaching leads to developing new skills through breaking bad habits and teaching proper techniques. Well developed skills and talents increase a department's efficiency. Furthermore, the improved communication between managers and subordinates results in an easy flow of information and ideas. Employees who feel free to communicate have a higher morale which is reflected in their interactions with co-workers and customers. This increase in morale and innovation should improve the organization's productivity as a whole (Knippen \& Green, 1990).

\section{Barriers to Coaching}

The literature of the early eighties also emphasized the barriers to coaching and why managers may be resistant to adapting this new style of management. One barrier is that some managers are intimidated by learning a different "style" that may diminish their authoritative power. Some managers believe that their employees' productivity is proof they are "good" managers. Others are simply afraid of change. Specifically, Orth, Wilkinson and Benfari (1987) discuss several factors that inhibit the coaching style of management. First, many managers are not rewarded for developing their employees. Therefore, they lack incentives and role models for change. Next, if there are no coaching role models, managers are not exposed to the benefits of coaching. Finally, changing someone's management style takes time, training and money to develop these skills.

As the understanding of the need for coaching has increased, the literature has began focusing on specific tools for developing and training coaching techniques. 
Specifically, recent coaching literature emphasizes the essential climate needed for coaching to be successful as well as certain traits or characteristics of a good coach.

\section{Coaching Climate}

In order for the coaching process to be successful, organizations must develop a climate committed to improving the employee's performance. Organizational climate involves employees' perception of the values and expectations essential to the culture (Schein, 1985). Therefore, for coaching to be successful, the organizational climate must be perceived as one of trust, respect and cooperation through which information is freely exchanged (Kinlaw, 1989). Both the manager and employees must mutually understand the other's expectations, hopefully resulting in measurable performance goals. This climate must encourage a free and open exchange of ideas (Orth, Wilkinson, \& Benfari, 1987). Most importantly, for coaching to be successful, the environment must be a supportive one in which the employee is encouraged to ask questions, take risks and make mistakes (Ottele \& Schaefer, 1991).

Evered and Selman (1989) explain the specifics involved in creating a climate of coaching. They recommend extensive education on coaching through workshops. Next, the organization must receive commitment from the educated managers to strive to "master" the coaching style. Finally, the organization should prepare for any problems produced by this change process. 


\section{Important Coaching Skills}

Since the role of the manager as coach is complex, it is important to discuss the essential skills he or she should have to be successful. Since coaching resembles on-the-job training, it involves the daily hands-on process of encouraging employees to take opportunities to improve performance. The coach must feel responsible for helping employees develop their capabilities daily and for the long term (Orth, Wilkinson, \& Benfari, 1987). Coaches must realize they and their employees are mutually dependent on each other for success. As Fournies (1987) plainly states, "accept that the management function is getting things done through others. Accept that you need them more than they need you...their success or failure reflects upon you" (p. 73).

Orth, Wilkinson and Benfari (1987) define four skills they believe are critical for successful coaching. First, a manager as coach must have excellent observational skills, which primarily involve measuring employee performance against set goals. Therefore, the manager must daily observe an employee's behavior and performance. Second, the manager as coach should also have analytical skills to identify opportunities for the employee to learn as well as when employees need coaching to improve their performance. Third, the manager as coach needs interviewing skills to ask correct questions and give appropriate responses. This involves learning when to ask open, closed or reflective questions. Finally, the coach must develop effective feedback techniques such as being specific, descriptive, and directing the feedback toward a potentially changeable behavior rather than criticizing an employee's personality. 
Cohen (1990) also described essential elements of good coaching. First, the manager must be accessible. He stressed the importance of making subordinates feel their emotions, doubts and concerns will be heard. Second, the manager needs to consistently give employees recognition for their achievements. Cohen describes praise as a simple and very effective motivator. Third, the manager should counsel his or her subordinates.

During these counseling sessions the manager should alsc ask the employee questions regarding the organization's strengths and weaknesses as well as personal aspirations and problems. Furthermore, Brown (1990) also stresses that an effective coach guides rather than controls his or her employees. The effective coach realizes that a feeling of interdependence among employees and striving for a common goal is crucial for organizational success in the nineties.

Overall, the concept of coaching has evolved into an important management tool that challenges managers to demand acheivement from their employees. Since the benefits of establishing a coaching climate are impressive, destroying the barriers certainly seems worth the effort. Organizations are realizing that encouraging employee development and risk taking by adapting a coaching style of management can greatly increase the effectiveness and innovation of their workforce.

\section{Current Coaching Models}

Since many organizations are enthusiastic about integrating the coaching management style into their own culture, the most recent literature has focused on various steps of effective coaching and effective "models" or pricesses. Kinlaw (1989) stresses 
that ineffective coaching results from random conversations between manager and subordinate that fail to follow a specific process. His coaching model consists of specific steps to achieve two basic goals: solving problems and improving performance. These are critical goals present in most models.

Though there are many variations, most current models, steps or processes of coaching consist of certain basic elements. The first step involves determining which skills need to be learned or improved and then establishing commitment from the employee to address these skills. Second, the goals of the learning must be clearly understood and discussed. This involves actively listening and asking probing questions. Third, specific techniques or procedures to improve the employee's knowledge or skills must be taught and demonstrated. Fourth, the employee must be given the opportunity to practice the skills and prove his or her abilities. Finally, and most importantly, the coach must monitor the progress and give effective feedback and praise (Knippen \& Green, 1990; Ottele \& Schaefer, 1991).

\section{Empirical Studies of Coaching}

Though the topic of coaching has been popular among management writers, it has been largely ignored by psychologists. The extensive studies on mentoring in the workplace (Burke \& McKeen, 1990; Noe, 1988; Ragins \& McFarlin, 1990) have overshadowed coaching research. Mentoring in the workplace may be easier to study since the mentoring relationship is not as complex as coaching. The mentor is an experienced employee who volunteers to convey his or her organizational knowledge, 
experience and guidance to the less experienced employee. This relationship is comparatively straight-forward. The mentor is expected to give the protégé career guidance, suggestions, helpful techniques, political tips and friendly support. The potential mentor is trained to listen, and advise. Therefore, studying a mentoring program may not be as complex as that of coaching since the focus is on what rather than how the mentor should teach.

In contrast, the management style of coaching can be seen as an intimidating test of one's flexibility. Organizations initiating these programs generally do not give managers a choice of whether or not to participate. Furthermore, the focus is not simply on creating a "teacher-student" relationship; these managers are expected to change their style of managing such that "how" they interact with their subordinates is suddenly significant. These managers are expected to "counsel," "motivate," develop a sense of "teamwork," "be sensitive to the subordinate's needs" and help the employees "grow." Compared to being a mentor, coaching seems like a formidable undertaking.

Therefore, the coaching literature has focused more on creating the proper climate for coaching, eliminating any barriers to coaching and describing the essential qualities of excellent coaches rather than on actual research. However, though empirical research on coaching is lacking, related studies on the topics of mentoring, modeling, delegation and participation, have revealed findings supporting coaching as an essential management tool. 
Olian, Carrol, Giannantonio and Feren (1988) studied the most important characteristics protégés look for in a mentor. Their results revealed that the mentor's interpersonal communication skills are the most important factor to a subordinate interested in having a mentor. These findings suggest that managers who are learning coaching skills need to consider their overall interpersonal communication skills as well. Though subordinates often select their mentor, they are unable to choose their manager-coach. Therefore, the manager as coach must integrate his or her learned coaching techniques with competent interpersonal skills to enhance one's effectiveness as a leader.

The empirical literature which focuses on modeling in the workplace also supports coaching as a way to improve individual development. Manz and Sims (1986) found that modeling a manager's behavior may help subordinates learn to lead themselves. They discovered that a manager's goal-setting behavior was modeled by subordinates who had observed this behavior on a videotape, even though there were no explicit instructions to do so. This research suggests that it is important for managers to model the coaching skills they learn. By actively showing concern for individual and team development, coaches will encourage subordinates to become "coaches" themselves.

The participation and delegation research also reveal some interesting findings. Research in participation has suggested it is an important technique for enhancing commitment to organizational decisions (e.g., Scweiger \& Leana, 1986; Vroom \& Jago, 1988). Burke (1986) also found that a climate encouraging participation and involvement 
in the decision making process increases employee commitment to the organization and profitability. Furthermore, Sashkin (1984) believes that a climate of nonparticipation may be harmful since it fails to provide healthy psychological needs.

In a study comparing the nature and effects of delegation and participative decision making, Leana (1987) discovered that managers were more likely to delegate responsibility when the decisions involved were less important and the manager felt overloaded. Most importantly, Leana found that delegation was correlated with higher subordinate performance and whether the managers believed their subordinates were capable. Leana (1987) concluded that when delegating a task, a manager considers the ability and dependability of the subordinate and delegates to the higher performer.

The Leana (1987) study reveals the complex decisions made by a manager who adopts a coaching style. Since a manager-coach may repeatedly delegate tasks to the same star performer, other subordinates miss the opportunity to prove their capabilities and fail to develop their skills and confidence as a result. A good coach needs to be aware of his or her natural tendencies to delegate to the same subordinate. By commissioning challenging tasks to subordinates who perform at a lesser level, the manager-coach can help them to improve their skills.

\section{Coaching Training}

Since training programs that teach managers how to adopt the management style of coaching are becoming prevalent and popular, it is important that empirical research explore the effectiveness of these programs. There are two aspects of coaching training 
that must be addressed when determining its effectiveness; the organizational climate and whether the learned skills are transferred to the job.

The literature has stressed that an organization's climate must be supportive and reinforce the learned skills in order for these skills to be transferred to the work environment (Bahn, 1973; Marx, 1982; Salinger, 1973). Therefore, î the manager who attends the coaching training program does not believe these new skills and behaviors will be supported by the organization, they will not be used. Since the goal of teaching coaching skills to managers is to help them develop their subordinates, it is just as important that the subordinates believe the organizational climate supports coaching as well. The subordinates will be motivated to use the development skills their managers have taught them if they believe the work environment supports these behaviors (Noe, 1986). By embracing their manager's commitment to support them in developing their full potential, these employees will become goal focused, productive workers.

Furthermore, since these training programs aim to improve the employees' behaviors by teaching the managers to develop committed, highly skilled workers, research is needed to determine if the managers actually transfer these learned coaching techniques to the job. Research by Nce (1986) stressed that continuously practicing the learned skills on the job increases the probability these skills will be maintained and change behaviors as a result. Therefore, empirical research should also determine if these coaching skills are still practiced months after the original training. 
This study explored the effectiveness of a coaching skills training session conducted for the managers of a medium sized government defense contractor. The overall purpose of this study was to determine if this coaching skills training program was effective in improving the participants' coaching skills within this organization. Specifically, the purpose of this research was threefold. First, to evaluate if the subordinate's view of whether the organization's climate was supportive of coaching changes over time. The second goal was to evaluate if the subordinate's view of how well his or her manager uses coaching skills changes over time. The third goal was to determine whether a subordinate believes that his or her manager continued to use the coaching skills taught through the coaching training program.

This study had four hypotheses:

(1) The subordinate's view of the level of support the organization's climate provides for coaching would be more positive one week after their manager's coaching training then before the training. The subordinate's belief that their organizational climate is conducive to coaching should become more positive since they have witnessed the organization's commitment to teaching their manager such skills and ideas. 
(2) The subordinate's view of their manager's coaching skills should be more positive one week after their manager's coaching training than before the training. The subordinate's rating of their manager's coaching skills should become more positive since they will have witnessed the managers using these skills during the training process.

(3) The subordinate's view of their manager's coaching skills should continue to change over time and become more positive ten weeks after the training. The subordinate's rating of their manager's coaching skills should increase from previous ratings. However, this change should only occur if the subordinates determine that their managers continue using the learned coaching skills. In other words, if the subordinates indicated ten weeks after the training that their managers continue using their coaching skills, their ratings of their manager's skills should increase.

(4) The correlation between the subordinate's view of the organizational climate and their manager's skills should be a positive one. Since the climate variable cannot be 
manipulated, it was used to determine how the relationship with the coaching skills variable changed over time.

Method

Subjects

Respondents were 48 employees of a government defense contractor. These employees came from four different departments within the organization, though most were computer operators with the title "satellite operations engineer." The respondents ranged in age from 28 to 51 years. Only 4 of the 52 respondents were women.

These respondents were chosen by 26 managers or supervisors who were asked to attend a coaching skills training program. These managers/supervisors were instructed through the training program's pre-assignment to choose two subordinates with whom to practice their learned coaching techniques during the three day program. Each of the managers/supervisors then notified two subordinates that he or she had been chosen to participate in this coachirg training program.

It is important to note that of the 48 subordinates only 17 completed all three surveys. Therefore, the results of this study were derived from these 17 respondents. However, the data collected from the entire sample population was also analysed for the purpose of comparison.

Approximately half of the managers/supervisors in this organization had already attended the coaching skills training program a year prior to this study. Therefore, this training was accepted as a management development plan to improve the coaching skills 
of all managers and supervisors. It was not seen as a "punishment" for those who lack coaching skills.

It is equally important to discuss the culture of the organization. During the time of this research project upper management announced that the organization was in a cost-cutting mode and layoffs might be a future possibility. However, no other management development training was being conducted around the time of this study which might affect the results of this research.

Since this organization offers technological services and support for government contracts rather than weapons, it is continuing to win contracts. Though the overall climate for this industry seems unstable, this organization sees a steady future. Therefore, the climate has been described as moderately "secure." The culture was an increasingly open one as the dress code is casual, and college graduates with computer skills continue to be hired.

Materials

A three-part questionnaire was developed. The purpose of the first section was to assess the subordinate's belief that the organizational climate supports coaching. The second section obtained ratings of their manager's coaching skills and the use of these skills over time. The third section collected background and demographic information.

The goal of the first section was to obtain data regarding the subordinate's view of their group or department's climate. This section was included in all three tests and did not change (see Appendix A). This section instructed the subordinates to consider their 
department or group as they mark their level of agreement to 15 statements. The items began with THIS GROUP/DEPARTMENT.... and continued with statements such as "promotes teamwork," "encourages me to ask questions," and "promotes a free and open exchange of ideas." They were instructed to circle the number corresponding to their level of agreement. This five point Likert type scale consisted of " 1 " = strongly disagree, "2" = disagree, "3" = sometimes agree, sometimes disagree, "4" = agree, "5" = strongly agree. Negative items in this scale were reverse coded so that a low score on this scale (1 or 2) would indicate a positive belief toward the coaching potential of their group/department's climate.

The second section of the questionnaire consisted of twenty to twenty-four statements that determined the subordinate's evaluation of their manager's coaching skills (see Appendix B). In the pre-test, this section began with twenty statements that were also included in the following two tests. The first post-test included three additional statements. The second post-test included the twenty-three statements of the first post-test as well as one additional statement.

In the pre-test, twenty statements began with MY SUPERVISOR/MANAGER.... and continued with statements such as "delegates risky, challenging tasks," "knows my strengths and weakness'," and "is available for advice and support." The same five point Likert type scale was used. Again, negative items in this scale were reverse coded so that a low score on this scale ( 1 or 2 ) indicated a positive belief toward the coaching skills of their manager/supervisor. 
In the first post-test this second section included the original twenty statements in the pre-test as well as an additional three questions (see Appendix C). The purpose of these additional questions was to determine whether the coach was actually using the skills learned in the coaching training program. These three questions are MY MANAGER/SUPERVISOR...."takes on the role of a coach on a daily basis," "clarified my development goals during the follow-up coaching session which we have had since the coaching training," and "would be open to having more coaching sessions if I felt the need."

In the second post-test, the second section was similar to the first post-test with an addition of one question (see Appendix D). The goal of this question was to determine if the manager/supervisor continued to use his/her learned coaching skills by coaching other subordinates besides the respondent. Therefore, this question stated MY MANAGER/SUPERVISOR... "seems to be initiating coaching sessions with my co-workers."

The third section of this questionnaire consisted of demographic items (see Appendix E). The respondents were asked to record their supervisor/manager's name, as well as their own position and title, organization number and whether they are salaried exempt or non-exempt. The organization for whom this research is being conducted requested that this demographics section be limited to ensure the participant's anonymity. This third section was included in the questionnaire packet in all three tests. 


\section{Procedure}

Each of the thirty managers/supervisors verbally informed his or her two subordinates that they had been chosen to participate in a coaching training program designed to improve the manager's coaching skills. As a part of the coaching training program, the manager/supervisor gave each subordinate a pre-workshop assignment they returned to the manager before the beginning of the three day session. This pre-workshop assignment included a pamphlet which described the role of a coach as well as the benefits of coaching. Next, the subordinates recorded the goals they would like to achieve. Finally, the subordinates were asked to complete a survey asking them to rate their manager/supervisor's current coaching skills.

The pre-workshop assignment for the manager/supervisors who attended the coaching training included an overall discussion of coaching as a management style. Next, the pamphlet asked the manager/supervisors to record their development goals. Finally, they were instructed to complete the survey in which they rated their own coaching skills.

The 52 subordinates who participated in their manager/supervisor's training program were sent the pre-test questionnaire through inter-organizational mail one week before the training. They were instructed to mail the completed questionnaire to the researcher within five days. Though the respondents were exposed to the training program through the pre-assignment, this should neither affect their rating of the climate's openness toward coaching nor their rating of their managers' coaching skills. 
The three day coaching skills training program began approximately one week after the pre-workshop assignments were completed. The first training day lasted five hours. During this time, the managers/supervisors were given resource guides on coaching skills which described important coaching skills. They were also instructed to complete a coaching plan to help them prepare for the coaching discussion they would have with their two subordinates. Through this plan, the manager/supervisor recorded development goals for their subordinates.

On the second day of training, the manager/supervisors met with each of their subordinates individually for approximately one hour. During this meeting they discussed the coaching plan developed the previous day. This plan included specific development and performance goals for the subordinate on which both agreed. They also discussed how the manager/supervisor could improve in becoming an effective coach for each subordinate.

The third day of training lasted five hours and began with an open session for the managers/supervisors to share their coaching experiences. The trainers also provided them with pamphlets on how to handle specific coaching situations such as career coaching. Finally, the managers/supervisors were instructed to have follow-up sessions with their two subordinates within the next one to two weeks. Furthermore, the managers/supervisors were encouraged to initiate coaching sessions with other subordinates as well. They were given pamphlets in their participant's packet to assist them in these future coaching sessions. 
The subordinates were mailed the first post-test survey one week after their manager/supervisor completed the training program. They were instructed to mail the completed questionnaire to the researcher within five days. This one to two week period gave the subordinates time to think about the coaching process in which they have been involved. During this time, the subordinates were able to consider their organization's climate and possible changes in their manager/supervisor's behavior since the training. Furthermore, this time period give the manager/supervisor a chance to initiate the follow-up coaching session.

The second post-test questionnaire was distributed approximately ten weeks after the initial training session. Again, the questionnaire was mailed to the subordinates with instructions to mail it back within five days. This ten week time period gave the subordinate an opportunity to witness any changes in the climate of their organization. Furthermore, the subordinates should have observed whether or not their manager/supervisor continued to use the coaching skills as well as their effectiveness.

Results

The overall means and standard deviations of both variables for the pre-test and both post-tests are presented on Table 1. Both the climate and skills variables indicated acceptable variance.

The first hypothesis analyzed the results of the climate variable. The means and standard deviations for climate from the pre-test and both post-tests are presented on Table 2. Three within-subject MANOVAs were conducted to determine if the means of 
the climate variable increased from the pre-test to the two post-tests. The first MANOVA analyzed the climate variable across the three time periods. The second MANOVA analyzed climate from the pre-test to the first post-test. The third MANOVA analyzed the climate variable between the two post-tests. All three MANOVA's revealed nonsignificant results, $[\underline{F}(2,32)=.55 \underline{p}=.58],[\underline{F}(1,16)=4.11 \underline{p}=.06],[\underline{F}(1,16)=.02 \underline{p}=$ .89 , respectively]. These results indicate that the participants' view of whether the organizational climate is conducive to coaching did not change over time; however, the increase from the pre-test to the first post-test approached significance.

The second hypothesis analyzed the results of the skills variable. The means and standard deviations for skills from the pre-test and both post-tests are presented on Table 2. As in the first hypothesis, three within-subject MANOVAs were conducted to determine if the means of the skills variable increased from the pre-test and both post-tests. The first MANOVA analyzed the skills variable across the three time periods. These results revealed a significant within-subject effect $[\underline{F}(2,30)=9.30 \underline{p}<.05]$. The second MANOVA analyzed skills from the pre-test and first post-test. These results also indicated a significant within-subject effect $[\underline{F}(1,15)=25.87 \underline{p}<.01]$. Therefore, the mean for the skills variable increased from the pre-test to the first post-test. Finally, the third MANOVA analyzed the skills variable from the first and second post-tests. These results did not reveal a significant within-subject effect $[\underline{F}(1,16)=.29 \underline{p}=.59]$. Overall, these results convey that the means for the skills variable increased from the pre-test to the first post-test. Therefore, the employees did rate their managers as having better 
coaching skills one week after the training session. However, since these means did not show a significant increase between the first and second post-test, the employees did not rate their managers higher on their coaching skills ten weeks after the training session.

The third hypothesis evaluated the results of the skills variable from the second post-test as well as the used/not used variable which was created from four additional questions on the second post-test. To determine the used/not used variable, the subjects' score for each of the four questions were summated. Once the midpoint of these summated scores was determined, a cut-off score equally divided the scores into those who use coaching skills the most ("used") and those who use coaching skills the least ("not used "). The means and standard deviations for both the first and second post-test with the used/not used variable are presented on Table 3. A within-subject MANOVA was then conducted with the skills variable from the first post-test and the second post-test by the categorical variable of used/not used. These results, $[\underline{F}(1,15)=7.03 \underline{p}<$ $.05]$, revealed a significant main-effect for the used/not used variable with those who continued using their coaching skills ("used"). As expected, there was no main effect for the first and second post-tests $[\mathrm{F}(1,15)=.22 \mathrm{p}=.64]$. The interaction between used/not used and time periods was also not significant $[\underline{F}(1,15)=1.43 \underline{\mathrm{p}}=.25]$. Overall, these results convey that the mean post-test scores on the combined skills scale were higher for those who continued to use their coaching skills.

The fourth hypothesis explored the relationship between the climate and skills variables in the pre-test and both post-tests. A Pearson correlation was run with the 
climate variable and the skills variable from the pre-tests. These results, $[\underline{I}(15)=.66 \mathrm{p}<$ $\left..01, \underline{\mathrm{r}}^{2}=.44\right]$, indicate a positive correlation between the climate and skill variables at the time of the pre-test. Next, a Pearson correlation was run with the climate and skills variable from the first post-test. These results also reveal a positive correlation between these two variables, $\left[\mathrm{r}(16)=.64, \mathrm{p}<.01, \underline{\mathrm{r}}^{2}=.41\right]$. Finally, a third Pearson correlation which was run with the climate and skills variable from the second post-test also indicated a positive correlation, $\left[\underline{r}(16)=.75, \underline{p}<.01, \underline{r}^{2}=.56\right]$. Overall, though the relationship between skills and climate decreases slightly at the first post-test, it peaks at the second post-test which indicates that their relationship strengthens over time in the ten week period between the two post-tests. 
Table 1

Means and Standard Deviations of Climate and Skills Variables at Three Time Periods

\begin{tabular}{lcccc}
\hline & & \multicolumn{3}{c}{ Time Period } \\
\cline { 3 - 5 } Variable & & Pre-test & Post-test 1 & Post-test 2 \\
& & & & \\
Climate & $\mathrm{M}$ & 3.54 & 3.62 & 3.64 \\
$(\underline{\mathrm{N}}=17)$ & $\mathrm{SD}$ & .32 & .37 & .59 \\
& & & & \\
Skills & $\mathrm{M}$ & 3.32 & 3.66 & 3.61 \\
$(\underline{\mathrm{N}}=17)$ & $\mathrm{SD}$ & .55 & .48 & .50 \\
\hline
\end{tabular}


Table 2

Means and Standard Deviations for Climate and Skills Variables MANOVA

Time Period

\begin{tabular}{|c|c|c|c|c|}
\hline & & Pre-test & Post-test 1 & Post-test 2 \\
\hline \multicolumn{5}{|l|}{ Climate } \\
\hline $\begin{array}{l}\text { MANOVA } 1 \\
(\underline{N}=17)\end{array}$ & $\begin{array}{l}\mathrm{M} \\
\mathrm{SD}\end{array}$ & $\begin{array}{r}3.54 \\
.32\end{array}$ & $\begin{array}{r}3.62 \\
.37\end{array}$ & $\begin{array}{r}3.64 \\
.59\end{array}$ \\
\hline $\begin{array}{l}\text { MANOVA } 2 \\
(\underline{N}=17)\end{array}$ & $\begin{array}{l}\mathrm{M} \\
\mathrm{SD}\end{array}$ & $\begin{array}{r}3.54 \\
.32\end{array}$ & $\begin{array}{r}3.62 \\
.37\end{array}$ & \\
\hline $\begin{array}{l}\text { MANOVA } 3 \\
(\underline{N}=17)\end{array}$ & $\begin{array}{l}\mathrm{M} \\
\mathrm{SD}\end{array}$ & & $\begin{array}{r}3.62 \\
.37\end{array}$ & $\begin{array}{r}3.64 \\
.59\end{array}$ \\
\hline \multicolumn{5}{|l|}{ Skills } \\
\hline $\begin{array}{l}\text { MANOVA } 1^{\mathrm{a}} \\
(\underline{\mathrm{N}}=17)\end{array}$ & $\begin{array}{l}\mathrm{M} \\
\mathrm{SD}\end{array}$ & $\begin{array}{r}3.31 \\
.50\end{array}$ & $\begin{array}{r}3.64 \\
.49\end{array}$ & $\begin{array}{r}3.61 \\
.51\end{array}$ \\
\hline $\begin{array}{l}\text { MANOVA } 2^{*} \\
(\underline{N}=17)\end{array}$ & $\begin{array}{l}\mathrm{M} \\
\mathrm{SD}\end{array}$ & $\begin{array}{r}3.32 \\
.55\end{array}$ & $\begin{array}{r}3.64 \\
.49\end{array}$ & \\
\hline $\begin{array}{l}\text { MANOVA } 3 \\
(\underline{N}=17)\end{array}$ & $\begin{array}{l}\mathrm{M} \\
\mathrm{SD}\end{array}$ & & $\begin{array}{r}3.66 \\
.49\end{array}$ & $\begin{array}{r}3.61 \\
.50\end{array}$ \\
\hline
\end{tabular}

a significant correlation exists only between pre-test and post-test 1 . ${ }^{*} \underline{p}<.01$ 


\section{Table 3}

Means and Standard Deviations for Skills and Used/Not Used MANOVA

\begin{tabular}{|c|c|c|c|c|}
\hline Variable & & Skills Post-test 1 & Skills Post-test 2 & Overall Mean \\
\hline $\begin{array}{l}\text { Used }^{\mathrm{a}} \\
(\underline{N}=16)\end{array}$ & $\begin{array}{l}\mathrm{M} \\
\mathrm{SD}\end{array}$ & $\begin{array}{r}3.87 \\
.55\end{array}$ & $\begin{array}{r}3.93 \\
.38\end{array}$ & 3.90 \\
\hline $\begin{array}{l}\text { Not Used } \\
(\underline{N}=18)\end{array}$ & $\begin{array}{l}\mathrm{M} \\
\mathrm{SD}\end{array}$ & $\begin{array}{c}3.47 \\
.34\end{array}$ & $\begin{array}{r}3.33 \\
.42\end{array}$ & 3.40 \\
\hline Overall Mean & & 3.67 & 3.63 & \\
\hline
\end{tabular}




\section{Post Hoc Analysis}

Since the size of the original sample population was smaller than anticipated, two subsequent sets of analyses were conducted for the purpose of comparison. The first set involved the data from the entire sample population. First, the overall mean differences and standard deviations for both the climate and skills scales at all three time periods were explored for the entire sample. These means and standard deviations are presented on Table 4. Moreover, the same analyses which examined the four hypotheses of this research were conducted for this expanded sample.

The second subsequent analysis involved all subjects excluding the seventeen who completed all three surveys. Due to the disproportional number of subjects who completed the second post-test, it was impractical to conduct the original analyses for this group. However, the overall means and standard deviations for these surveys were studied for the purpose of comparison. These results are presented on Table 5.

The overall means of the climate scale for the entire sample population increased at the first post-test and then decreased below the pre-test level at the time of the second post-test. However, the overall means of the skills scale for the entire sample population followed the same pattern as that of the original sample population. The first post-test scores increased while the second post-test scores decreased below those of the first post-test. Moreover, when the same four analyses which were run on the original sample were also used to analyze the entire sample population, the results were similar for each 
analysis. Finally, the overall means of both the climate and skills scales for the entire sample population excluding the seventeen subjects revealed the same trend as that of the original sample population. These results support the pattern which convey the means increasing at the first post-test and then decreasing after the second post-test below those of the pre-test. 
Table 4

Means and Standard Deviations of Climate and Skills Variables at Three Time Periods - Entire Sample Population

Time Period

Variable

Pre-test Post-test 1 Post-test 2

Climate

$\begin{array}{cccc} & (\underline{\mathrm{N}}=46) & \underline{\mathrm{N}}=27) & (\underline{\mathrm{N}}=25) \\ \mathrm{M} & 3.62 & 3.64 & 3.57 \\ \mathrm{SD} & .56 & .50 & .66\end{array}$

Skills

$\begin{array}{cccc} & (\underline{\mathrm{N}}=45) & \underline{\mathrm{N}}=28) & (\underline{\mathrm{N}}=25) \\ \mathrm{M} & 3.61 & 3.76 & 3.60 \\ \mathrm{SD} & .58 & .43 & .57\end{array}$


Evaluating Coaching

\section{Table 5}

Means and Standard Deviations of Climate and Skills Variables at Three Time Periods -Excluding Seventeen Subjects

Time Period

Variable Pre-test Post-test $1 \quad$ Post-test 2

$\begin{array}{lcccc}\text { Climate } & & (\underline{\mathrm{N}}=29) & (\underline{\mathrm{N}}=10) & (\underline{\mathrm{N}}=8) \\ & \mathrm{M} & 3.66 & 3.67 & 3.43 \\ & \mathrm{SD} & .66 & .70 & .81 \\ \text { Skills } & & (\underline{\mathrm{N}}=29) & (\underline{\mathrm{N}}=11) & (\underline{\mathrm{N}}=8) \\ & \mathrm{M} & 3.77 & 3.92 & 3.56 \\ & \mathrm{SD} & .55 & .30 & .73\end{array}$




\section{Discussion}

This study explored a coaching skills training program to determine its effectiveness in improving the participant's coaching skills within this organization. A survey completed at three different time periods focused on the organizational climate as well as the skills of managers who participated in the training. The purpose of this research was threefold. First, this study evaluated whether the subordinate's view of the organizational climate's openness toward coaching changed over time. Secondly, this study sought to determine if the subordinate's view of the effectiveness of his or her manager 's coaching skills changed over time. Finally, this study tried to discover if the subordinates believed that their manager continued to actually use the learned coaching skills.

The first hypothesis, which explored whether ratings on the climate variable changed over time, was not supported. The subordinates did not significantly change their ratings of the organization's openness toward coaching over the three time periods surveyed. Implications of this finding will be further discussed in the following pages.

On the other hand, the second hypothesis, which explored whether the subordinates' ratings of their manager's coaching skills changed over time, revealed interesting and partially significant results. The subordinates did increase their ratings of their manager's coaching skills one week after the training. Apparently, the subordinates 
witnessed their managers using coaching skills during their coaching conversations and believed these skills improved. Therefore, the first part of this hypothesis was supported. However, the second part of this hypothesis was not supported since the second post-test scores were no higher, and in fact decreased, from the first post-test scores. Therefore, the subordinates did not believe that their managers continued to improve their coaching skills ten weeks after the training.

The third hypothesis explored the skills variable and those managers who did or did not continue to use their coaching skills. These results were consistent with the results from hypothesis two which conveyed no increase in scores on the skill scale between the two post-tests. Therefore, the subordinates did not increase the rating of their manager's coaching skills when they were surveyed ten weeks after the training. However, the managers who continued to use their coaching skills ("used") were more likely to have higher scores on the skill scale than those who did not continue to use their coaching skills ("not used".) In other words, the second part of hypothesis three was supported since a correlation exists between whether the managers continue to use their coaching skills and how they were rated on the skill scale. Apparently, the managers who continued to use their coaching skills one week or ten weeks after the training were recognized by their subordinates who rated them as being more effective coaches.

The fourth hypothesis explored the relationship between the climate and skills variables and discovered a significant and positive correlation between these variables at all three time periods. Though the correlations remained significant, the first post-test 
correlation decreased slightly from that of the pre-test. However, the correlation between these two variables was strongest at the second post-test. This suggests that the relationship between the ratings from the climate and skills scales strengthened over ten weeks.

\section{Post Hoc Analysis}

Due to the small sample size of the original seventeen who completed all three surveys, two further sets of analyses were necessary for comparison. Interestingly, these analyses seemed to support those of the original sample population. The overall skills scale means for the entire sample population, as well as the results from the four analyses, are similar to those from the original sample. Furthermore, results derived from the overall climate and skills scales means for the entire sample population excluding the seventeen subjects also reveal the same pattern as those from the original sample.

On the other hand, comparing the overall climate scale means from the original sample population with the two subsequent analyses reveals interesting results. The overall climate scale means for the original seventeen who completed all three surveys increased at the first post-test and then continued to increase at the second post-test. However, the overall climate means from both the entire sample population and those excluding the seventeen subjects increased at the first post-test and then decreased below the pre-test level at the time of the second post-test. Since the overall climate means from both subsequent analyses differed from the original sample population, the original 
seventeen subjects who completed all three surveys may have had a different perspective on the organization's climate. This implication will be dicussed further.

\section{Implications}

Though the results of the original analysis did not support hypothesis one, the overall means of the climate variable have interesting implications. The fact that the mean scores for the original 17 subjects continued to increase even at the second post-test is evidence that this group differs from the entire sample population. It is very possible that these original 17 subordinates are satisfied and devoted employees who completed all three surveys due to their enthusiasm toward their jobs. These employees may be high achievers who are eager to please their manager and organization. Therefore, as the research of Leana (1987) revealed, these star performers are more likely to be delegated challenging tasks. Since these employees may be receiving the benefits of coaching, they may be content with the climate as a result.

The second hypothesis conveyed an interesting pattern. The subordinates did see a noticeable improvement in their manager's coaching skills one week after the training. However, this evidence also conveys that they do not believe that their manager's coaching skills continued to improve ten weeks after the training. Their managers may not be practicing and reinforcing coaching skills on the job as Noe (1986) stressed in order to change their behavior. 
Moreover, the means from the skills variable suggest that the training may have raised the subordinate's expectations since they participated in helping their managers become coaches. It is possible that the subordinates observed their manager using coaching skills for the first time through the coaching conversation exercise as well as the follow-up session. However, ten weeks later, it appears that many of these subordinates realized that their managers failed to continue using their learned coaching skills. Therefore, because the subordinates' expectations for change had not been met, ten weeks after the training they rated their managers lower on the skills survey.

The results from the third hypothesis clarifies the beneficial effects that coaching had on these employees. The subordinates in this organization seem to believe that those managers who continue using their coaching skills have more effective coaching and management skills than those who do not coach. This evidence should be very motivating to all managers who are sincerely interested in improving their management techniques.

It is interesting to note that the results of the fourth hypothesis reveal that the mean scores for both scales were lowest at the second post-test. This decrease in mean scores and strong relationship between the climate and skills scales may again indicate the employees' disappointment that their managers had not become better coaches. As the weeks progressed and many managers failed to change their behavior, the subordinates may have witnessed how the organization's climate clearly influences their manager's actions and attitudes. At the time of the pre-test, the relationship between the organization's climate and the manager's skills may have seemed distinct. However, 
during the first post-test and certainly ten weeks later during the second post-test, the training process itself may have helped the subordinates to understand the important link between a manager's skills and a climate which supports or ignores coaching as a management tool.

Overall, this study provided interesting patterns which unveil important implications. The results from both the climate and skill scales convey that the subordinates increased their manager's ratings in the survey taken one week after the training. Then, ten weeks later, the subordinate's ratings of their managers skills decreased below those from the first post-test. This pattern may depict the subordinates' disappointment that their expectations for improved coaching were not met. Most importantly, the results reveal their positive feelings toward the coaching behaviors their managers used during coaching conversations and exercises in which they participated. The subordinates seemed to believe that the managers who continued to coach were the most effective managers.

Clearly, this study illuminates the importance of continuous reinforcement. Bahn (1973), Marx (1982), and Salinger (1973) emphasize the importance of an organizational climate which supports and reinforces newly learned management skills. They also stress reinforcing learned skills to insure that managers transfer them to their work environment. It is crucial for these managers to know that upper management values coaching and expects to see them coach on a daily basis. 
Reinforcing these coaching skills would be especially important in an environment that is insecure due to economic woes and possible layoffs. Specific training which reinforces the learned coaching skills would build the participants' confidence and feelings of security within the organization. It would convey that even though the organization is in a cost-cutting mode, upper management wants and expects its employees to improve. The organization values their skills and believes they can improve and change them to avoid layoffs. This would give the employees a sense of control that their actions can improve the efficiency and quality of their organization.

Becoming a coach is challenging and intimidating since it requires the managers to delegate responsibility and encourage their employees' development. It is very easy for a manager to disregard his or her coaching training as too time consuming and risky. Therefore, these managers need specific guidelines to help them follow-through on their coaching conversations. Upper management might state that they expect the managers to have coaching conversations with each of their employees by a certain deadline. Followthrough should be monitored. The managers could be required to keep a separate journal which tracks their subordinates' development. This information would be discussed in the performance review process.

The training department, with the support of upper management, might have monthly coaching meetings in which the managers discuss their coaching successes and difficulties among coworkers. It would be beneficial if a "coaching expert" were present 
as well. Ideas and solutions could be shared which would give the participants moral support as well as specific solutions to their coaching problems.

Upper management must be very clear of their expectations for these potential coaches. Consequently, tying the effectiveness of the managers' coaching skills to their own performance review would be the most important and effective way to prove that upper management expects these techniques to show real results.

\section{Evaluation of the Study}

Most importantly, this research reveals the positive effect coaching training has on employees. In this study, most subordinates believed that their managers' coaching skills became more effective one week after the coaching training. Moreover, the managers who reportedly continued using their coaching skills were considered to be more effective than the managers who did not continue using these skills. Therefore, the subordinates in this organization seemed to notice an improvement in their manager's behavior after the coaching training. These facts should encourage coaching skills trainers, supporters and managers alike.

Furthermore, this study clearly illustrates the need for a process which effectively reinforces learned coaching skills. A standardized system which will continuously motivate and reinforce coaching skills should develop managers who will coach throughout their management years.

However, though there was no other training introduced to this organization during this research, employee morale may have weakened since one month following the 
training, upper managment announced they were in a cost-cutting mode. The possibility of future layoffs was discussed as well. It is believed that these facts, combined with the currently ailing economy, may have intensified employees' feelings of job insecurity.

Since people are less open and enthusiastic to learn new techniques in a slightly unstable work environment, some of the managers who participated in the coaching training may not have felt confident enough to embrace these new skills. If these managers believed their own positions were at risk, they were probably threatened by the coaching ideas of "delegating" "risk taking" and giving their subordinates career guidance. Therefore, the insecurity of this organization may explain why the subordinates believed that the climate did not improve over time.

These facts may also explain why, after ten weeks, only seventeen subordinates out of forty-six, completed all three surveys. The other subordinates may have doubted management's commitment to the coaching training while cost-cutting and layoffs were looming overhead.

Finally, it is possible that the climate survey was too broad in scope to reflect the potential climate changes which the coaching training may have introduced. The subordinates may have considered the organization as a whole rather than focusing on the "group" or "organization" which is supervised by the training participant.

\section{Future Research}

Clearly, many organizations of the 90 's which value continuous improvement through employee empowerment will embrace coaching as an essential management style. 
However, research which evaluates the effectiveness of specific coaching training programs is lacking.

Once the environment in which the coaching training will be conducted is considered stable, there are many aspects of coaching on which to focus. Future studies should examine whether younger managers really adopt the coaching style more readily than senior managers. This subject alone could become very complex. Studies may find that managers who have spent many years within the organization find coaching more difficult than newer managers. Most importantly, if either of these hypotheses are true, how can coaching training effectively impact these different individuals?

As more women and minorities join the workforce and reach management levels, future coaching research should address how the coaching style of management influences these groups specifically. Do men and women respond differently to coaching and being coached? Will a women employee respond as well to a male coach and vice versa? Does adopting a coaching style increase or decrease a women's chance of breaking the glass ceiling?

Multiculturalism in current organizations will effect coaching training as well. Coaching research would benefit by answering several important questions. Does coaching foster a sense of supportive teamwork which might help minorities grow within the organization? Do employees of certain cultures adapt to coaching or being coached easier than others? Also, it would be important to address the criteria on which coaching training participants are judged. These criteria may be culturally biased. Since coaching is 
a complex management style, organizations must ensure that their training and evaluations will benefit its unique employees as well as fit the corporate climate. The tone and focus of coaching training can determine whether successful transfer of training will occur.

Organizations of the Nineties are determined to fully develop their human resource potential. Managers who coach encourage employees to create, innovate and continuously improve. Further evaluations of coaching training will continue to help organizations develop high quality performers. 


\section{References}

Aurelio, S., \& Kennedy, J.K. (1991). Performance coaching: A key to effectiveness.

Supervisory Management, $\underline{36}$, 1-2.

Bahn, C. (1973). The countertraining problem. Personnel Journal, 28, 1068-1072.

Brown, T. (1990). Boss-or coach? Industry Week, $\underline{239}, 8$.

Burke, R.J., \& McKeen, C.A. (1990). Mentoring in Organizations: Implications for women. Journal of Business Ethics, $\underline{9}, 317-332$.

Cohen, W.A. (1990). The art of the leader. Englewood Cliffs, NJ: Prentice Hall.

Evered, R., \& Selman, J. (1989). Coaching and the art of management.

Organizational Dynamics, 19 , 16-32.

Fournies, F.F. (1987). Coaching for improved work performance United States: Liberty Hall Press.

Harrison, R. (1983). Strategies for a new age. Human Resource Management, $\underline{22}$, 209-235.

Hollander, E.P. \& Offermann, L.R. (1990). Power and leadership in organizations. American Psychologist, 45, 179-189.

Kanter, R.M. (1983). The change masters. New York: Simon \& Schuster.

Kanter, R.M. (1989 November-December). The new managerial work. Harvard Business Review, pp. 85-92. 
Kinlaw, D.C. (1989). Coaching for commitment: Managerial strategies for obtaining superior performance. San Diego: University Associates, Inc.

Knippen, J.T., \& Green, T.B. (1990). Coaching. Management Accounting, 71, 36-38.

Leana, C.R. (1987). Power relinquishments versus powersharing: Theoretical clarification and empirical comparison of delegation and participation. Journal of Applied Psychology, 72, 228-233.

Lord, R.G., DeVader, C.L., \& Alliger, G.M. (1986). A meta-analysis of the relation between personality traits and leadership perceptions: An application of validity generalization procedures. Journal of Applied Psychology, 71, 402-409.

Manz, C.C., \& Sims, H.P., Jr. (1986). Beyond imitation: Complex behavioral and affective linkages resulting from exposure to leadership training models. Journal of Applied Psychology, 71, 571-578.

Marx, R.D. (1982). Relapse prevention for management training: A model for maintenance of behavior change. Academy of Management Review, 7, 433441.

Noe, R.A. (1986). Trainee's attributes and attitudes: Neglected influences on training effectiveness. Academy of Management Review, 11, 736-749.

Noe, R.A. (1988). Women and mentoring: A review and research agenda. Academy of Management Review, 13, 65-78. 
Olian, J.D., Carroll, S.J., Giannantonio, C.M., \& Feren, D.B. (1988). What do proteges look for in a mentor? Results of three experimental studies. Journal of Vocational Behavior, 33, 15-37.

Orth, C.D., Wilkinson, H.E., \& Benfari, R.C. (1987). The manager's role as coach and mentor. Organizational Dynamics, $15,66-74$.

Ottele, R.G., \& Schaefer, B. (1991). How to provide effective on-the-job coaching for your staff. The Practical Accountant, 24, 70-72.

Ragins, B.R., \& McFarlin, D.B. (1990). Perceptions of mentor roles in cross-gender mentoring relationships. Journal of Vocational Behavior, 37, 321-339.

Salinger, R. (1973). Disincentives to effective employee training and development. Washington, DC: U.S. Civil Service Commission.

Sashkin, M. (1984). Participative management is an ethical imperative. Organizational Dynamics, $12,4-22$.

Schein, E.H. (1985). Organizational culture and leadership. San Francisco: Jossey-Bass.

Schweiger, D.M., \& Leana, C.R. (1986). Participation in decision making. In E.A. Locke (Ed.), Generalizing from laboratory to field settings (pp.147-166). Lexington, MA: Heath.

Vroom, V.H., \& Jago, A.G. (1988). The new leadership: Managing participation in organizations. Englewood Cliffs, NJ: Prentice-Hall.

Walton, R.E. (1985). From control to commitment in the workplace. Harvard Business Review, $\underline{63}, 77-84$. 


\section{Appendix A}

HOW TO ANSWER: Read each statement carefully. To the right of each statement circle the number which best describes your agreement or disagreement with the item. Circle only one number for each item, and please respond to all items.

This survey should not take more than 15 minutes to complete.

NOTE: Answer all items while considering your department and manager in (this organization).

1 = strongly disagree

2 = disagree

$3=$ sometimes agree, sometimes disagree

$4=$ agree

$5=$ strongly agree

\section{THIS DEPARTMENT....}

1. Promotes a free and open exchange of ideas

12345

2. Encourages mutual trust and respect

12345

3. Does not honor uniqueness

12345

4. Is a supportive and helping environment

12345

5. Believes it is important that I expand my

12345

capabilities and improve my performance, and skills

12345

6. Seems committed to control and maintaining their authority

12345

7. Promotes teamwork and shared responsibility

12345

8. Cooperates regarding the sharing of information

12345

9. Has open communication channels

12345

10. Discourages me from asking questions

12345

11. Lets me express iny concern over problems and conflicts

12345

12. Enables me to challenge myself without fear of punishment

12345

13. Gives rewards which are consistent with accomplishments

12345

14. Does not view continuous improvement as a high priority

12345

15. Encourages people to help each other 
Appendix B

$1=$ strongly disagree

$2=$ disagree

$3=$ sometimes agree, sometimes disagree

$4=$ agree

$5=$ strongly agree

\section{MY MANAGER...}

1. Has confidence in my abilities and potential

12345

2. Knows my strengths and weaknesses

12345

3. Does not delegate risky, challenging tasks

12345

4. Is committed to my development for future opportunities

12345

5. Identifies opportunities for me to expand my capabilities

12345

6. Gives recognition through praise

12345

7. Helps me to choose specific development goals

12345

8. States clear goals, priorities, and expectations

12345

9. Is rarely available for advice and support

12345

10. Listens actively

12345

11. Freely shares his/her expertise with others

12345

12. Has an attitude which is helpful and empathetic

123345

13. Discourages autonomy

12345

14. Asks critical questions to help me identify problems and solutions

12345

15. Builds my self-confidence and esteem

12345

16. Gives instructive, specific feedback without criticism

12345

17. Is unclear on who does what by when

12345

18. Focuses on solving problems rather than placing blame

12345

19. Informs me of changes, and decisions within the organization

12345

20. Assigns projects which fit my talents and interests 
Appendix C

$1=$ strongly disagree

2 = disagree

3 = sometimes agree, sometimes disagree

$4=$ agree

$5=$ strongly agree

\section{MY MANAGER...}

1. Takes on the role of a coach on a daily basis

2. Clarified my development goals during the follow-up coaching session/s which we have had since the HOS training

12345

3. Would be open to having more coaching sessions if I felt the need

12345

4. Has confidence in my abilities and potential

5. Knows my strengths and weaknesses

12345

6. Does not delegate risky, challenging tasks

12345

7. Is committed to my development for future opportunities

12345

8. Identifies opportunities for me to expand my capabilities

12345

9. Gives recognition through praise

12345

10. Helps me to choose specific development goals

12345

11. States clear goals, priorities, and expectations

12345

12. Is rarely available for advice and support

12345

13. Listens actively

12345

14. Freely shares his/her expertise with others

12345

15. Has an attitude which is helpful and empathetic

12345

16. Discourages autonomy

12345

17. Asks critical questions to help me identify problems and solutions

12345

18. Builds my self-confidence and esteem

12345

19. Gives instructive, specific feedback without criticism

12345

20. Is unclear on who does what by when

12345

21. Focuses on solving problems rather than placing blame

12345

22. Informs me of changes, and decisions within the organization

23. Assigns projects which fit my talents and interests 


\section{Appendix D}

1 = strongly disagree

2 = disagree

3 = sometimes agree, sometimes disagree

$4=$ agree

$5=$ strongly agree

\section{MY MANAGER...}

1. Takes on the role of a coach on a daily basis

2. Clarified my development goals during the follow-up coaching session/s which we have had since the HOS training

12345

3. Would be open to having more coaching sessions if I felt the need

12345

4. Seems to be initiating coaching sessions with my co-workers

12345

5. Has confidence in my abilities and potential

12345

6. Knows my strengths and weaknesses

12345

7. Does not delegate risky, challenging tasks

12345

8. Is committed to my development for future opportunities

12345

9. Identifies opportunities for me to expand my capabilities

12345

10. Gives recognition through praise

12345

11. Helps me to choose specific development goals

12345

12. States clear goals, priorities, and expectations

12345

13. Is rarely available for advice and support

12345

14. Listens actively

12345

15. Freely shares his/her expertise with others

12345

16. Has an attitude which is helpful and empathetic

12345

17. Discourages autonomy

12345

18. Asks critical questions to help me identify problems and solutions

12345

19. Builds my self-confidence and esteem

12345

20. Gives instructive, specific feedback without criticism

12345

21. Is unclear on who does what by when

12345

22. Focuses on solving problems rather than placing blame

12345

23. Informs me of changes, and decisions within the organization

12345

24. Assigns projects which fit my talents and interests 
Appendix E

Please answer the following questions:

Your supervisor/manager's name:

Your position and title:

Organization \#:

Please circle one: Salaried exempt Salaried non-exempt 